\title{
Social research design: framework for integrating philosophical and practical elements
}

Kathryn Cunningham

\begin{tabular}{|l|l|}
\hline Date of deposit & 15032021 \\
\hline $\begin{array}{l}\text { Document } \\
\text { version }\end{array}$ & Author's accepted manuscript \\
\hline Access rights & $\begin{array}{l}\text { Copyright @ 2014 RCNi. This work has been made available } \\
\text { online in accordance with publisher policies or with } \\
\text { permission. Permission for further reuse of this content should } \\
\text { be sought from the publisher or the rights holder. This is the } \\
\text { author created accepted manuscript following peer review and } \\
\text { may differ slightly from the final published version. }\end{array}$ \\
\hline $\begin{array}{l}\text { Citation for } \\
\text { published version }\end{array}$ & $\begin{array}{l}\text { Cunningham, K 2014, 'Social research design: framework for } \\
\text { integrating philosophical and practical elements', Nurse } \\
\text { Researcher, vol. 22, no. 1, pp. 32-37. }\end{array}$ \\
\hline $\begin{array}{l}\text { Link to published } \\
\text { version }\end{array}$ & \begin{tabular}{l} 
https://doi.org/10.7748/nr.22.1.32.e1276 \\
\hline
\end{tabular}
\end{tabular}

Full metadata for this item is available in St Andrews Research

Repository at: https://research-repository.st-andrews.ac.uk/

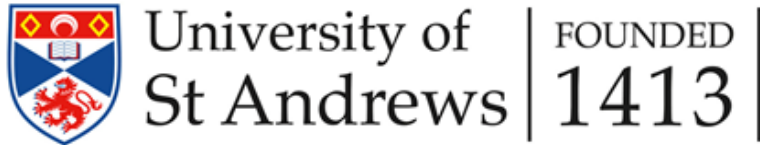


As a relatively inexperienced social researcher, I began my $\mathrm{Ph} . \mathrm{D}$. research project in the area of loneliness and cancer by searching for advice concerning the process of designing social research. The search revealed an abundance of textbooks (for example, Blaikie, 2010; Creswell, 2009; Crotty, 1998; Greener, 2011; Robson, 2002/2004) and journal articles (for example, Bryman, 2007; Carter and Little, 2007; Darlaston-Jones, 2007; Grix, 2002; Mesel, 2013) on the topic. Examination of this literature, coupled with attendance at conference presentations in which more experienced researchers detailed the process of designing their research, led to my recognition of inconsistencies and incongruities in the process of designing social research: some researchers/theorists endorse philosophical elements (ontological and epistemological assumptions and theoretical perspective [see Table 1 for definitions]) as the starting point of a research study and believe these to be of paramount importance in the research design (for example, Grix, 2002; Mason, 2002/2003). Others advocate exclusively practical elements (issue to be addressed, purpose, aims and research questions) (see Table 1 for definitions) as the beginnings of a research project and view these as the sole contributors to research design. It is unusual to see this view detailed in writing as research design is rarely discussed in empirical papers and theoretical texts on the process of research design generally mention the importance of philosophical assumptions. It is more common however to hear researchers promote this view when discussing research design in conference presentations. Still others regard both philosophical and practical elements as highly-important factors contributing to the design of a social research project, however provide little clarity regarding the ways in which the factors integrate chronologically and informatively (for example, Creswell, 2009; Crotty, 1998). It is of little surprise then that the design stage of the research process has been described as "bewilder[ing]", "unclear" and "contradictory" (Crotty, 1998, p. 1). 
Given that social research begins with "a real-life issue to be addressed, a problem to be solved or a question to be answered" (Crotty, 1998) and that philosophical assumptions are "inescapable" (Carter and Little, 2007, p. 1319) as "all knowledge is knowledge from some point of view" (Fishman, 1978, p. 531), both philosophical and practical elements are of significance in the design of social research. The presence and influence of practical elements in social research design is straightforward - the research is underlain by a purpose and aims and serves to answer research questions; however the relevance of philosophical elements to social research design is less self-evident particularly for those trained exclusively in quantitative research. The general acceptance of the rigour and value of quantitative methods has rendered unnecessary a discussion of philosophical elements and their contribution to the research design (Maykut and Morehouse, 1994). This is not to say that such elements have no influence on the design of quantitative research indeed their consideration and discussion in such research design would actually be of great value (Mason, 2002/2003). In all types of social research philosophical elements influence (either explicitly or implicitly) the practical elements and the methodology ("the strategy, plan of action, process or design lying behind the choice and use of particular methods and linking the choice and use of methods to the desired outcomes" [Crotty, 1998, p. 3]) and methods (the specific techniques used to collect and analyse data [Creswell and Plano Clark, 2007]) selected for use in a research study. The researcher's explicit awareness and understanding of his/her philosophical assumptions and theoretical perspective, and their interactions with practical elements in the selection of research methodology and methods, is thus of considerable importance, facilitating coherent research design - including employment of congruent quality-assurance techniques - and enabling well-founded and meaningful conclusions (Carter and Little, 2007; Crotty, 1998; Flowers, 2009; Greener, 2011; Morrow, 2005; Silverman, 2000; Willig, 2008). The requirement for conjoint consideration 
and explication of philosophical and practical elements thus deems problematic the lack of clear and coherent guidance regarding the integration of these elements in the design of social research.

\section{Framework Integrating the Elements Influential in the Design of Social Research}

In response to this problematic deficiency, I engaged in extensive consideration of the inter-relationships between the influential elements in the process of social research design and developed a guiding framework that incorporates all of these elements and clearly delineates interactions and relationships between them. This framework is relevant for all types of social research (qualitative, quantitative and mixed methods) and is illustrated in Figure 1. Definitions of the framework elements are provided in Table 1. I do not claim it necessary for all of the relationships included in the framework to exist in every research project; however I do believe a number of relationships to be fundamental in the design of all social research:

1. An informative relationship between issue to be addressed, purpose, aims and research questions

2. An informative relationship between philosophical assumptions and both research questions and methodology/methods

3. An informative relationship between theoretical perspective and both research questions and methodology/methods

4. An informative relationship between research questions and methodology/methods

I also do not claim the framework to be exhaustive of all potential relationships. I simply offer it as a tool to guide social researchers with the design - and explication of the design of their research, and intend that it aid in abating the confusion regarding the chronological 
and informative integration of practical and philosophical elements in this stage of the research process.

Figure 1: Framework integrating philosophical and practical elements in the process of social research design

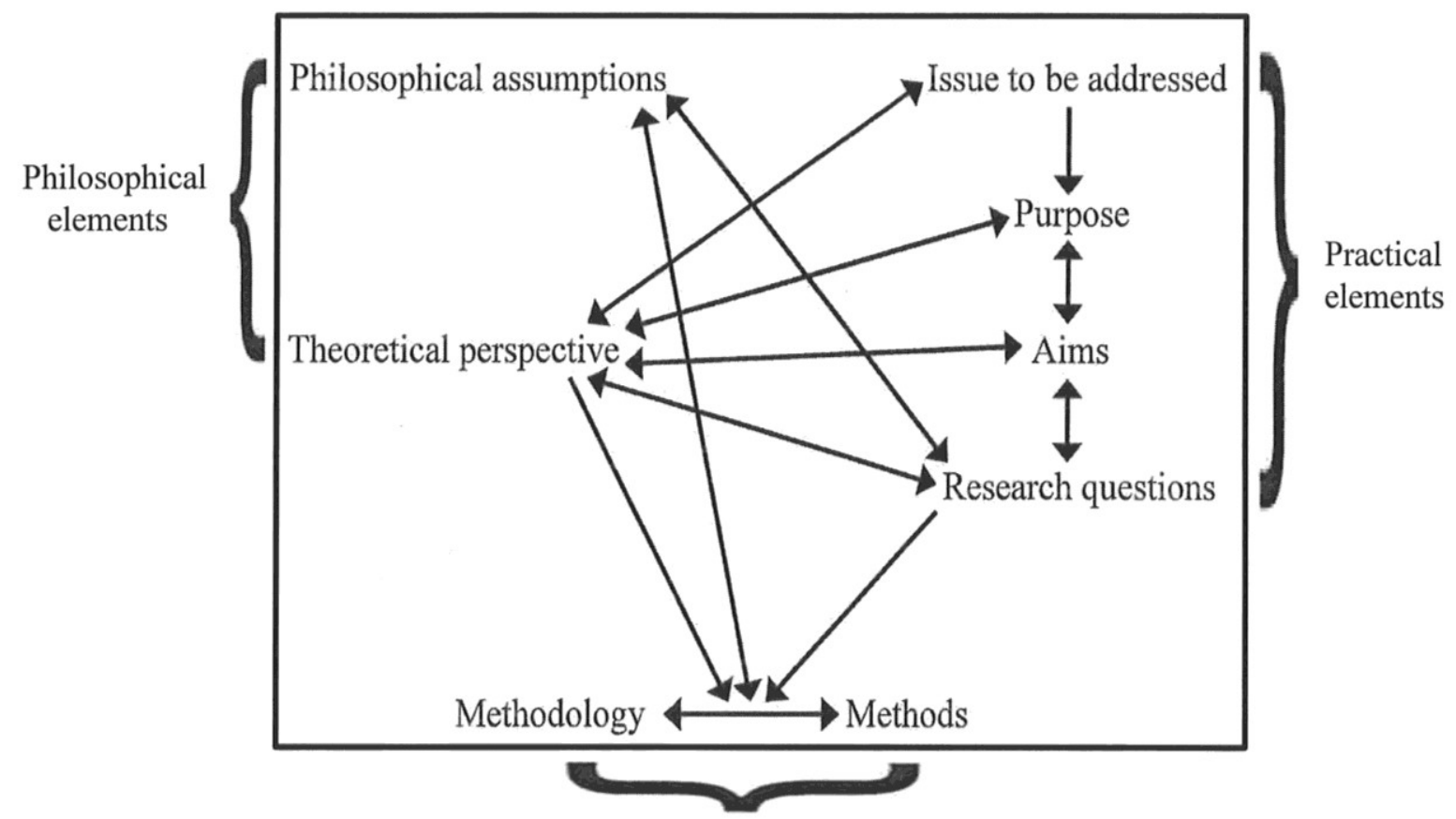

End products 


\begin{tabular}{ll} 
Element of framework & Definition \\
\hline Issue to be addressed & The real-life issue to be addressed/problem to be \\
& solved/question to be answered (Crotty, 1998) \\
\hline Purpose & The broad reason for undertaking the research \\
\hline Aims & The specific intentions of the research study \\
\hline Research questions & The questions to be answered by the study in order to \\
& fulfill the aims
\end{tabular}

\begin{tabular}{ll}
\hline Philosophical assumptions: & "What it is possible to know about the world" (Snape \\
- Ond Spencer, 2003, p. 19) \\
- Epistemological \\
"How it is possible to find out about the world" (Snape \\
assumptions \\
"The philosophical stance informing the methodology \\
and thus providing a context for the process and \\
grounding its logic and criteria" (Crotty, 1998, p. 3)
\end{tabular}

Table 1: Definitions of the elements of the process of social research design

\section{Discussion}

To explain the framework and elucidate the inter-relationships between elements I will make reference to my $\mathrm{Ph} . \mathrm{D}$. research project in the area of loneliness and cancer. It is useful then to begin by introducing the elements influential in the design of my Ph.D. project and the end-products of methodology and methods selected. These are depicted in Figure 2. 
Figure 2: The elements and end-products of my Ph.D. research project design

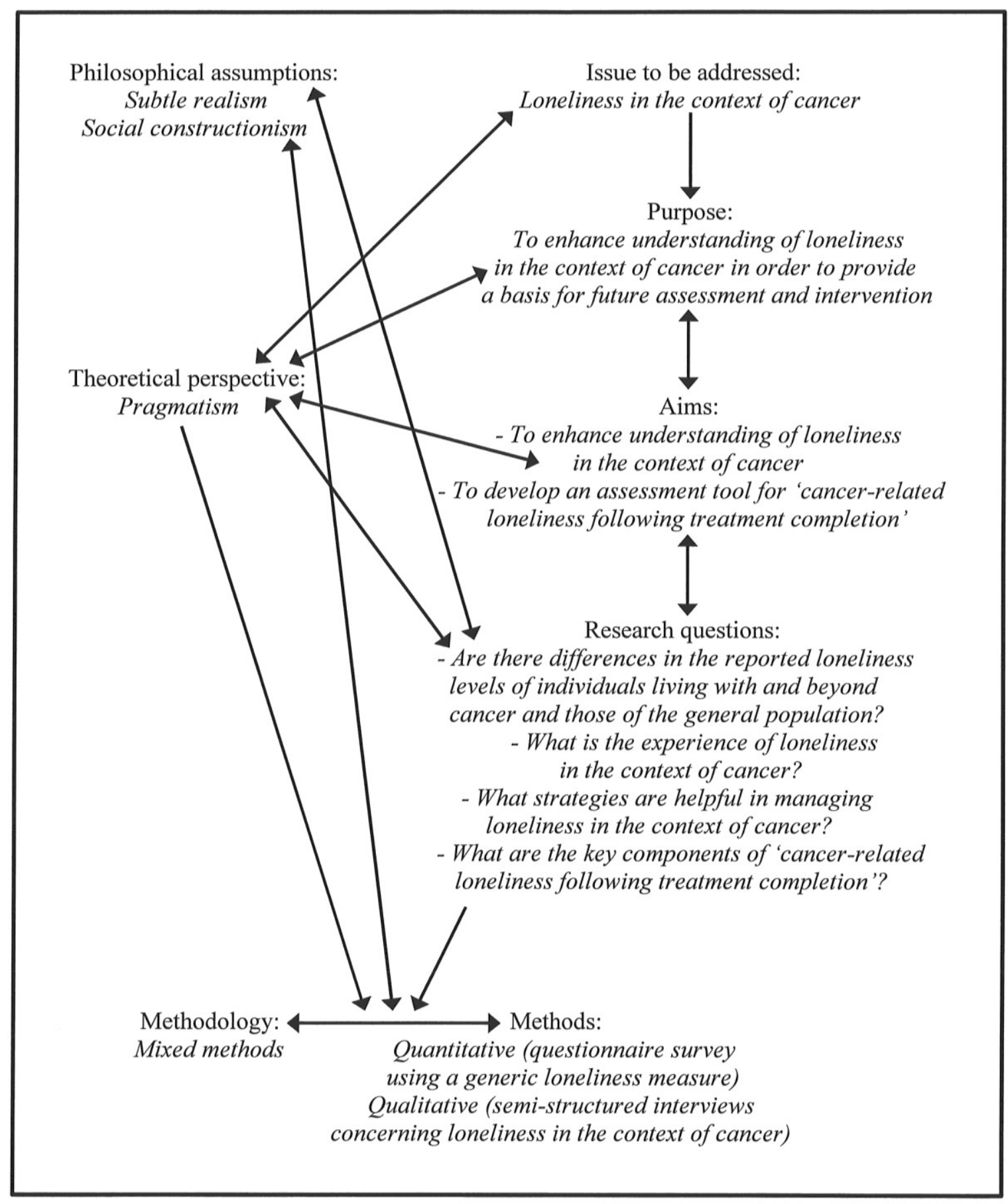


The elements of the framework are inextricably intertwined and no definitive 'starting point' exists - the researcher can begin by considering his/her philosophical assumptions or theoretical perspective or the issue to be addressed. The decision concerning the chronological order in which to consider elements must be taken on an individual project basis. In the case of my Ph.D. project, the practical and applied nature dictated that attention be directed first and foremost to the practical elements of the research design (issue to be addressed, purpose, aims and research questions). Definition of these elements was an iterative process due to the exploratory nature of the research. Originating from the wish to address the issue of loneliness in the context of cancer, the research began with a literature review that enabled the identification of gaps in current knowledge and understanding of loneliness in people living with and beyond cancer. This resulted in the formulation of the study aim: To enhance understanding of loneliness in people living with and beyond cancer, and the empirical research questions: Are there differences in the reported loneliness levels of individuals living with and beyond cancer and those of the general population?, What is the experience of loneliness in the context of cancer?, and What strategies are helpful in managing loneliness in the context of cancer? The empirical work undertaken to answer the second and third of these questions identified a unique context-specific loneliness termed cancer-related loneliness following treatment completion. The observation that assessment of, and development and evaluation of interventions to address, this context-specific loneliness were impeded by the absence of a measure of such loneliness engendered a further study aim: To develop an assessment tool for 'cancer-related loneliness following treatment completion', and its corresponding research question: What are the key components of 'cancer-related loneliness following treatment completion'? In line with the suggestion of Robson (2002/2004) that following development of other elements of a study it may be necessary to review the purpose, the purpose of the current study was refined following the 
development of the aims and research questions: the general wish to address the issue of loneliness in the context of cancer advanced to the more specific purpose: To enhance understanding of loneliness in the context of cancer in order to provide a basis for future assessment and intervention.

The next element of consideration was that of theoretical perspective. In my $\mathrm{Ph}$.D. project the elements of issue to be addressed, purpose, aims and research questions held a reciprocal relationship with the theoretical perspective: the practical and applied nature of the project prompted the adoption of a pragmatic theoretical perspective; however my training in the pragmatic discipline of health psychology led me to select a real-world problem to be solved (Cornish and Gillespie, 2009; Robson, 2002/2004). Pragmatism refers to an approach to research that emphasises the functional consequences of knowledge (Schuh and Barab, 2008). It views knowledge as a "tool for action" (Cornish and Gillespie, 2009, p. 800 ) and the question shifts from "Does this knowledge accurately reflect the underlying reality?" to "Does this knowledge serve our purposes?" (Cornish and Gillespie, 2009, p. 802). The maxim of a pragmatic theoretical perspective is that the methodology and methods most appropriate to answer the research questions and fulfil the aims of the study - be they qualitative, quantitative or a combination of both - should be those selected for utilisation (Bryman, 2006; Cornish and Gillespie, 2009; Johnson and Onwuegbuzie, 2004). A pragmatic perspective is believed by some to excuse the researcher from considering the philosophical assumptions underlying his/her research, and to justify the 'anything goes' attitude of "methodological eclecticism" (Teddlie and Tashakkori, 2012, p. 776); however, the inescapability of philosophical assumptions (Carter and Little, 2007; Fishman, 1978) dictates the co-existence of a pragmatic perspective and philosophical assumptions concerning knowledge (Mesel, 2013). 
It may appear logical then to proceed next to the discussion of the philosophical assumptions underlying my Ph.D. research; however, as a relatively inexperienced researcher I had never before considered my own philosophical assumptions and their impact on a research project. After struggling with deep and abstract questions concerning these assumptions, and as a pragmatic researcher, I was relieved to discover advice stating that research questions and methods reflect the researcher's understanding of the world, therefore it is possible to expose his/her implicit philosophical assumptions by working in the reverse direction (Fielzer, 2010; Harrits, 2011). Discussion of the philosophical assumptions underlying my $\mathrm{Ph} . \mathrm{D}$. research will therefore be preceded by discussion of the methodology and methods selected; however, awareness and understanding of my philosophical assumptions enabled further development of the methodology and methods, thus these will be returned to following discussion of my philosophical assumptions.

As mentioned previously, the maxim of a pragmatic theoretical perspective is that the methodology and methods should be selected based on their ability to answer the research questions and fulfil the aims of the study (Cornish and Gillespie, 2009; Johnson and Onwuegbuzie, 2004). In my Ph.D. project the research questions commanded the use of both qualitative methods (semi-structured interviews and thematic framework analysis) and quantitative methods (questionnaire survey and descriptive and inferential statistical analysis), therefore the study employed a mixed methods methodology, where this refers to:

the type of research in which a researcher or team of researchers combines elements of qualitative and quantitative research approaches (e.g., use of qualitative and quantitative viewpoints, data collection, analysis, inference techniques) for the broad 
purposes of breadth and depth of understanding and corroboration (Johnson et al., 2007, p. 123).

The mixed methods design was sequential and greater emphasis was placed on the qualitative phase than on the quantitative phase (Creswell and Plano Clark, 2007).

Despite the increasing popularity of mixed methods research (Harrits, 2011), particularly in applied health sciences (Alise and Teddlie, 2010; Forthofer, 2003), this type of research is not without its critics. Proponents of the "incompatibility of methods thesis" (Teddlie and Tashakkori, 2012, p. 777) believe the distinction between qualitative and quantitative methods to lie at the level of philosophical perspectives, thus denying epistemologically-coherent mixing of methods (Yanchar and Williams, 2006). Viewing the distinction instead at the level of methods dispels such incompatibility. My belief on this issue is akin to those of Crotty (1998), Hammersley (1992/1993) and Johnson and Onwuegbuzie (2004): epistemologies do not entail fixed methodologies and methods, therefore, although a combination of epistemologies would be questionable, a combination of quantitative and qualitative methods proves unproblematic. This is not to advocate the adoption of the 'anything goes' attitude of methodological eclecticism, but is rather to enable and encourage the design and conduction of epistemologically-congruent mixed methods research.

The final element to be considered was that of philosophical assumptions. These are intrinsic to the design and conduct of research, exerting an influence on all stages of the research process (Mesel, 2013). Their explicit acknowledgment and consideration is necessary in order that their covert influence does not "lead [the researcher] into error" (Hammersley, 1992/1993, p. 43). Their transparency aids in the informed and assumptioncongruent selections of methodologies and methods and the employment of appropriate 
quality-assurance techniques, thus facilitating coherent findings and conclusions (Carter and Little, 2007; Crotty, 1998; Flowers, 2009; Greener, 2011; Morrow, 2005; Silverman, 2000; Willig, 2008). Their transparency also enables others to appreciate the assumptions and to understand and therefore not wrongly criticise the findings and conclusions of a research study (Crotty, 1998; Grix, 2002; Willig, 2008).

Following the advice of Fielzer (2010) and Harrits (2011) mentioned above, I considered my research questions and methods and determined my personal belief that the phenomenon of loneliness exists but is only accessible through the human mind. I was thus able to elicit my implicit ontological stance as that of subtle realism and my implicit epistemological stance as that of social constructionism. The premise of subtle realism is that "an external reality exists independent of our beliefs and understanding [but] reality is only knowable through the human mind and socially constructed meanings" (Snape and Spencer, 2003, p. 16). Subtle realism thus preserves the idea of naïve realism that independent, knowable phenomena exist, however renounces the belief of naïve realism that those phenomena can be accessed directly, positing instead that all knowledge is a human construction (Hammersley, 1992/1993, Hammersley, 2011). Social constructionism postulates that "all knowledge, and therefore all meaningful reality as such, is contingent upon human practices, being constructed in and out of interaction between human beings and their world, and developed and transmitted within an essentially social context" (Crotty, 1998, p. 42). A social constructionist approach differs from an objectivist approach in that it does not view meaning as "inhere[nt] in the object, merely waiting for someone to come upon it" (Crotty, 1998, p. 43). Neither does it view meaning as "created out of whole cloth and simply imposed upon reality" (Crotty, 1998, p. 43) as does a subjectivist approach. Rather social constructionism views meaning as constructed in the interaction of the object and the subject, thus it sits between, and brings together, the epistemological polar opposites of 
objectivism and subjectivism (Crotty, 1998). In the process of research, meaning results from an interaction between the researcher and the participants, thus is 'co-constructed' (Darlaston-Jones, 2007). My aforementioned belief that methods are a-philosophical enabled compatibility between a social constructionist epistemological stance and both the qualitative and quantitative methods employed in the current study. As acknowledged by Johnson and Onwuegbuzie (2004), Morrow (2005) and Wells et al. (2012), the researcher undertaking quantitative research plays an active role in the research process and holds certain values (i.e. beliefs, feelings, etc. [Bryman, 2004]), thus, although unconventional, quantitative methods fit within a social constructionist epistemology (Burr, 1995; Crotty, 1998).

As stated previously, awareness and understanding of my philosophical assumptions enabled further development of the methodology and methods of the study. It facilitated selection of appropriate techniques for ensuring the quality of the research, for example, the provision of an audit trail of decisions (Long and Johnson, 2000) and the use of reflexivity (the acknowledgement and discussion of the role and influence of the researcher on the research project [Barbour, 2001]), in order to consider and explicate my influence on both the qualitative and quantitative phases - a necessary undertaking in research conducted from a social constructionist epistemological stance. Awareness and understanding of my philosophical assumptions also permitted certainty regarding the congruence of the research design.

This discussion of the elements influential in the design of my Ph.D. research project has underscored the importance of considering both practical and philosophical elements in conjunction in the design of social research. Such conjoint consideration and explication facilitates rigorous and coherent research design, enabling well-founded and meaningful conclusions.

\section{Conclusion}


In response to the lack of clear and coherent guidance regarding the integration of philosophical elements (ontological and epistemological assumptions and theoretical perspective) and practical elements (issue to be addressed, purpose, aims and research questions) in the design of social research, this paper has presented a guiding framework that incorporates all of these elements and clearly delineates interactions and relationships between them. It has drawn upon the author's $\mathrm{Ph} . \mathrm{D}$. research into loneliness and cancer for explanation and elucidation of the framework. It is hoped that this framework will aid other social researchers with the design - and explication of the design - of their research, thereby enhancing the credibility of their projects and enabling their research to establish wellfounded and meaningful conclusions.

\section{References}

Alise M, Teddlie C (2010) A continuation of the paradigm wars? Prevalence rates of methodological approaches across the social/behavioral sciences. Journal of Mixed Methods Research. 4, 103-126.

Barbour RS (2001) Checklists for improving rigour in qualitative research: a case of the tail wagging the dog? British Medical Journal. 322, 1115-1117.

Blaikie N (2010) Designing Social Research. Second edition. Polity Press, Cambridge. Bryman A (2004) Social Research Methods. Second edition. Oxford University Press, New York.

Bryman A (2006) Paradigm peace and the implications for quality. International Journal of Social Research Methodology. 9, 111-126.

Bryman A (2007) The research question in social research: what is its role? International Journal of Social Research Methodology. 10, 5-20.

Burr V (1995) An Introduction to Social Constructionism. Routledge, London. 
Carter SM, Little M (2007) Justifying knowledge, justifying method, taking action: epistemologies, methodologies, and methods in qualitative research. Qualitative Health Research. 17, 1316-1328.

Cornish F, Gillespie A (2009) A pragmatist approach to the problem of knowledge in health psychology. Journal of Health Psychology. 14, 800-809.

Creswell JW, Plano Clark V (2007) Designing and Conducting Mixed Methods Research. Sage Publications, Thousand Oaks.

Creswell JW (2009) Research Design: Qualitative, Quantitative, and Mixed Methods Approaches. Sage Publications, Thousand Oaks.

Crotty M (1998) The Foundations of Social Research: Meaning and Perspective in the Research Process. Sage Publications, London.

Darlaston-Jones D (2007) Making connections: the relationship between epistemology and research methods. The Australian Community Psychologist. 19, 1, 19-27.

Fielzer MY (2010) Doing mixed methods research pragmatically: implications for the rediscovery of pragmatism as a research paradigm. Journal of Mixed Methods Research. 4, 6-16.

Fishman M (1978) Crime wave as ideology. Social Problems. 25, 531-543.

Flowers P (2009) Research philosophies - importance and relevance [Course notes]. Glasgow Caledonian University, Glasgow.

Forthofer MS (2003) Status of mixed methods in the health sciences. In Tashakkori A, Teddlie C (Eds) Handbook of Mixed Methods in Social and Behavioral Research. Sage Publications, Thousand Oaks, 527-540.

Greener I (2011) Designing Social Research: A Guide for the Bewildered. Sage Publications, London. 
Grix J (2002) Introducing students to the generic terminology of social research. Politics. 22, 175-186.

Hammersley M (1993) What's Wrong with Ethnography? Methodological Explorations. Routledge, London. (Original work published 1992)

Hammersley M (2011) Methodology: Who Needs It? Sage Publications, London.

Harrits GS (2011) More than method?: A discussion of paradigm differences within mixed methods research. Journal of Mixed Methods Research. 5, 150-166.

Johnson RB, Onwuegbuzie AJ (2004) Mixed methods research: A research paradigm whose time has come. Educational Researcher. 33, 14-26.

Johnson RB, Onwuegbuzie AJ, Turner LA (2007) Toward a definition of mixed method research. Journal of Mixed Methods Research. 1, 112-133.

Long T, Johnson M (2000) Rigour, reliability and validity in qualitative research. Clinical Effectiveness in Nursing. 4(1), 30-37.

Mason J (2003) Qualitative Researching. Second edition. Sage Publications, London. (Original work published 2002)

Maykut P, Morehouse R (1994) Beginning Qualitative Research: A Philosophic and Practical Guide. The Falmer Press, London.

Mesel T (2013) The necessary distinction between methodology and philosophical assumptions in healthcare research. Scandinavian Journal of Caring Sciences. 27, 750756.

Morrow SL (2005) Quality and trustworthiness in qualitative research in counseling psychology. Journal of Counseling Psychology. 52, 250-260.

Robson C (2004) Real World Research: A Resource for Social Scientists and PractitionerResearchers. Second edition. Blackwell Publishing, Malden. (Original work published 2002) 
Schuh KL, Barab SA (2008) Philosophical perspectives. In Spector JM, Merrill MD, van Merrienboer JJG, Driscoll MP (Eds) Handbook of Research on Educational Communications and Technology. Third edition. Lawrence Erlbaum Associates, New York, 67-82.

Silverman D (2000) Doing Qualitative Research: A Practical Handbook. Sage Publications, London.

Snape D, Spencer L (2003) The foundations of qualitative research. In Ritchie J, Lewis, J (Eds) Qualitative Research Practice. Sage Publications, London, 1-23).

Teddlie C, Tashakkori A (2012) Common "core" characteristics of mixed methods research: A review of critical issues and call for greater convergence. American Behavioral Scientist. 56, 774-788.

Wells M, Williams B, Treweek S, Coyle J, Taylor J (2012) Intervention description is not enough: evidence from an in-depth multiple case study on the untold role and impact of context in randomised controlled trials of seven complex interventions. Trials. 13(95): http://www.ncbi.nlm.nih.gov/pmc/articles/PMC3475073/pdf/1745-6215-13-95.pdf (Last accessed: August 19 2013.)

Willig C (2008) Introducing Qualitative Research in Psychology. McGraw-Hill Professional Publishing, Berkshire.

Yanchar SC, Williams DD (2006) Reconsidering the compatibility thesis and eclecticism: five proposed guidelines for method use. Educational Researcher. 35, 3-12. 